\title{
Condena moral, temor político y provecho mercantil: actitudes y políticas españolas ante las "borracheras" indígenas (frontera de la Concepción de Chile, siglo XVIII)
}

Sebastián Leandro Alioto*

Fecha de recepción: 30 de marzo de 2020. Fecha de aceptación: 30 de septiembre de 2020

\section{Resumen}

En toda la América indígena, los festines colectivos resultaron eventos de sociabilidad de primer orden. Las borracheras fueron en Chile una de las principales dificultades afrontadas por los misioneros cristianos para convertir a los nativos, también las autoridades civiles y militares las consideraban peligrosas porque podían generar rebeliones y levantamientos. La venta de alcohol a los indios fue tradicionalmente rechazada hasta que, en ocasión del Parlamento de 1793 y tras recabar varias opiniones, el gobierno español decidió incentivar el comercio de bebidas alcohólicas con los indígenas ¿Por qué quienes tradicionalmente se habían opuesto a la introducción de alcohol en la frontera ahora, en abrumadora mayoría, la avalaban y recomendaban con énfasis? A través de diversas fuentes, que incluyen las opiniones solicitadas a varios actores coloniales, trataremos de contestar esta pregunta examinando la situación económica de la frontera penquista hacia fines del siglo XVIII, cuyos avatares explican en buena medida las reacciones de los interesados.

Moral condemnation, political fear and mercantile profit: Spanish attitudes and policies in the face of Indian borrachera feasts (frontier of Concepción de Chile, $18^{\text {th }}$ century)

\footnotetext{
Abstract

Throughout the native Americas, collective feasts were important events of sociability. In Chile, Indian borracheras were considered one of the main difficulties Christian missionaries had to face in order to convert natives, also civilian and military authorities considered them dangerous because they could lead to rebellions and uprisings. Therefore, the sale of alcohol to the

* Departamento Humanidades, Universidad Nacional del Sur. Consejo Nacional de Investigaciones científicas y Técnicas (CONICET). Bahía Blanca, Pcía. de Buenos Aires, Argentina. E-mail: seba.alioto@gmail.com
}

Palabras clave

frontera

Chile

indígenas

alcohol
Key words

frontier Chile Indians alcohol 
1. Los nativos de la Araucanía los denominaban cahuines en la lengua local, el mapu zungum (cfr. Febrés, 1765: 435). El abate Molina explicaba que los "convites, que suelen durar dos ó tres dias, se llaman cahuin o círculos, porque alrededor de un gran ramo de canelo se sientan en circulo á comer y beber" (Molina, [1787] 1795: 122).
2. Utilizamos esta grafía, típica de la época colonial, para señalar que no se trataba de conchabo en tanto relación o contrato de trabajo -como se ha utilizado después-, sino de una actividad de intercambio comercial.
Indians was traditionally rejected until, on occasion of the Parlamento of 1793 and after obtaining several favorable opinions in this regard, the Spanish government decided to encourage the trade of alcoholic beverages with the natives. Why did those who had traditionally opposed the introduction of alcohol at the border now overwhelmingly endorsed and recommended it with emphasis? Through different sources, which include the opinions requested from several colonial actors, we will try to answer this question, examining the economic situation of the Concepción's frontier towards late 18th century, whose avatars explain the reactions of the interested parties to a large extent.

\section{Introducción}

A lo largo de toda la América indígena, los festines colectivos -aquellas ocasiones altamente estandarizadas en que los participantes compartían abundantemente bebidas alcohólicas y alimentos- resultaron eventos de sociabilidad de primer orden. En ellos, las comunidades consolidaban sus lazos sociales o creaban otros nuevos; los líderes o los aspirantes a serlo reunían a sus seguidores con el anzuelo de la comida y la bebida; y las personas celebraban todos los hitos importantes de la vida, como el nacimiento, el matrimonio o la muerte (Saignes, 1993; Dietler, 2001, 2006; Pardo, 2004; Jennings, 2014).

Las borracheras, como los españoles solían llamar a estas fiestas, ${ }^{1}$ fueron consideradas como una de las principales dificultades que debían afrontar los misioneros cristianos en su tarea de convertir a los nativos americanos (Dailey, 1968; Salazar-Soler, 1993; Conrad, 1999; Azevedo Fernandes, 2004, 2007), dado que en ellos el alcohol circulaba profusamente, nublando las conciencias y llevando a los indios -siempre según la óptica misional- por caminos errados y lejanos a la buena policía y a los mandamientos evangélicos (Corcuera de Mancera, 1991).

Religiosos de varias órdenes y procedencias suscribieron a esa opinión, y los misioneros venidos a territorio chileno no fueron la excepción. Desde su temprana aparición en la frontera araucana la consideraron una grave dificultad para la conversión de los indios, en combinación con otras costumbres que socavaban desde las bases la forma de vida cristiana que querían imponerles.

Al mismo tiempo, las autoridades civiles y militares del régimen colonial sospechaban que los festines y los efectos del alcohol podían generar venganzas, alteraciones del orden e ímpetus de rebelión contra los españoles, comenzando una chispa de violencia que, en el campo fértil de la fricción interétnica, podía tener consecuencias imprevisibles.

Por esos motivos, y otros que veremos, religiosos y seglares condenaban el uso del alcohol entre los indios e impulsaron la prohibición de la venta a los indígenas de bebidas alcohólicas producidas por los cristianos, tornando ilegal el comercio que los conchavadores ${ }^{2}$ llevaban adelante en este ramo. Sin embargo, en buena medida las cosas cambiaron radicalmente en 1793, cuando Ambrosio Higgins requirió las opiniones de varios de los actores fronterizos sobre el comercio de vino con los indios ¿Cómo y por qué ocurrió este radical cambio de mirada?; a través de numerosas fuentes, muchas de ellas inéditas, trataremos de contestar esta pregunta y otras conexas. 


\section{Religiosos y seglares españoles contra el uso y el tráfico de alcohol entre los mapuche}

El consumo colectivo de bebidas alcohólicas y de alimentos es de gran relevancia para sociedades "tradicionales", trátese de sociedades sin Estado o de Estados antiguos. Al llegar a América, los españoles se encontraron con comunidades que usaban de los festines como cemento social preferencial. En las tierras que lograron conquistar, buscaron imponer sobre las poblaciones sometidas un nuevo orden social cuyo control exigía tener a raya los festines y las borracheras, considerados como un peligro por la oportunidad que daban a los congregados de recordar el pasado prehispánico y las ofensas recibidas, y de coordinar acciones que pudieran tener como objetivo atacar al régimen colonial o a sus representantes.

En México, por ejemplo, los misioneros deploraron inmediatamente el gusto de los indios por el pulque -octli en náhuatl-, al que achacaban todos los males de los nativos, incluyendo "la idolatría, la rebelión, la pobreza, la enfermedad, los crímenes con violencia, la infidelidad y el incesto" (Taylor, 1987: 68, en Corcuera de Mancera, 1991: 115). En el primer medio siglo colonial, el pulque perdió su uso ritual y de élite, el número de bebedores se amplió, lo mismo que las ocasiones para beber; además de que la bebida fue ahora sujeta a comercialización (Corcuera de Mancera, 1991: 115).

En los Andes, los españoles se enfrentaron a una larga tradición de bebidas colectivas, que durante la época incaica estuvieron firmemente reguladas por el Estado. La Iglesia las consideró "causa de todo mal" (Salazar-Soler, 1993: 35) y los europeos, al contrario que los incas, estimularon el consumo privado e individual de alcohol, prohibiendo -sin demasiado éxito- las reuniones para beber (Saignes, 1993).

En el caso del sur de Chile, la cosa se complica aún más porque no se trataba aquí de indígenas sometidos al control colonial sino de grupos que escaparon de él a partir de una larga resistencia, que terminó conformando una región de frontera, friccionada e inestable pero a la vez porosa y fuente de constantes interacciones que, si no excluían la violencia, se basaron cada vez más, a medida que avanzamos hacia el siglo XVIII, en la búsqueda de una convivencia pacífica (Villalobos, 1989; Zavala Cepeda, 2008). ${ }^{3}$

Los mapuche bebían bebidas fermentadas -genéricamente denominadas chichas en el mundo colonial, y mudai en la lengua local- hechas de muy diversas plantas nativas desde tiempos prehispánicos, a las que luego se agregaron las traídas por los españoles. Las ocasiones para hacer cahuines eran variadas: parlamentos para tratar la guerra o la paz, nacimientos, bodas, funerales, siembras, cercamientos, cosechas, construcción de casas, entre otras. ${ }^{4}$ Aquí también la costumbre de beber colectivamente fue juzgada negativamente por los españoles, y vista como raíz de diversos males.

Los padres jesuitas creían que, a pesar de vivir engañados por el demonio, los nativos mapuche no estaban exentos de gracia: el duro trabajo de evangelización resultaba al menos en la posibilidad de bautizarlos e integrarlos así a la cristiandad, aunque persistieran entre sus costumbres la poligamia, los cahuines y los machitunes (Foërster, 1995: 30). Pero los misioneros encontraban dificultades en la siembra de la palabra divina: el padre Covarrubias veía diablos en:
3. Aunque en el valle central de Chile -que los españoles dominaban- los pobladores indígenas encomendados o sometidos a control colonial también fueron protagonistas de borracheras que preocuparon a las autoridades obligándolas a tomar diversas medidas. Al respecto ver las fuentes compiladas por Contreras Cruces (2014). En el último cuarto del siglo XVI y la primera mitad del siguiente, los españoles temieron que la afluencia de indios de guerra desnaturalizados o encomendados desde la frontera meridional y las borracheras que compartían con sus congéneres locales, sólo parcialmente cristianizados e integrados en la sociedad colonial, dieran lugar a rebeliones en el propio núcleo del dominio hispano: "las referencias a las borracheras no se acababan en el consumo desmedido de alcohol, y sus consecuencias en el ausentismo laboral, sino que apuntaban a establecer el conjunto de prácticas que se derivaban de ello, entre las que se contaban las pendencias, el libertinaje sexual y la adoración al demonio o a otros espíritus no cristianos. Cada una de ellas era un paso hacia atrás en el proceso de integración a la sociedad colonial y su permanencia o, incluso, su retorno a la 'barbarie'. En tal reflexión, de ahí a la rebelión solo había un paso." (Contreras Cruces, 2018: 104).

4. Al respecto ver, Carvallo y Goyeneche (1876: 158-159); Pérez García ([1810]: 1900: 42); Pardo (2004) y Villar y Jiménez (2007). 


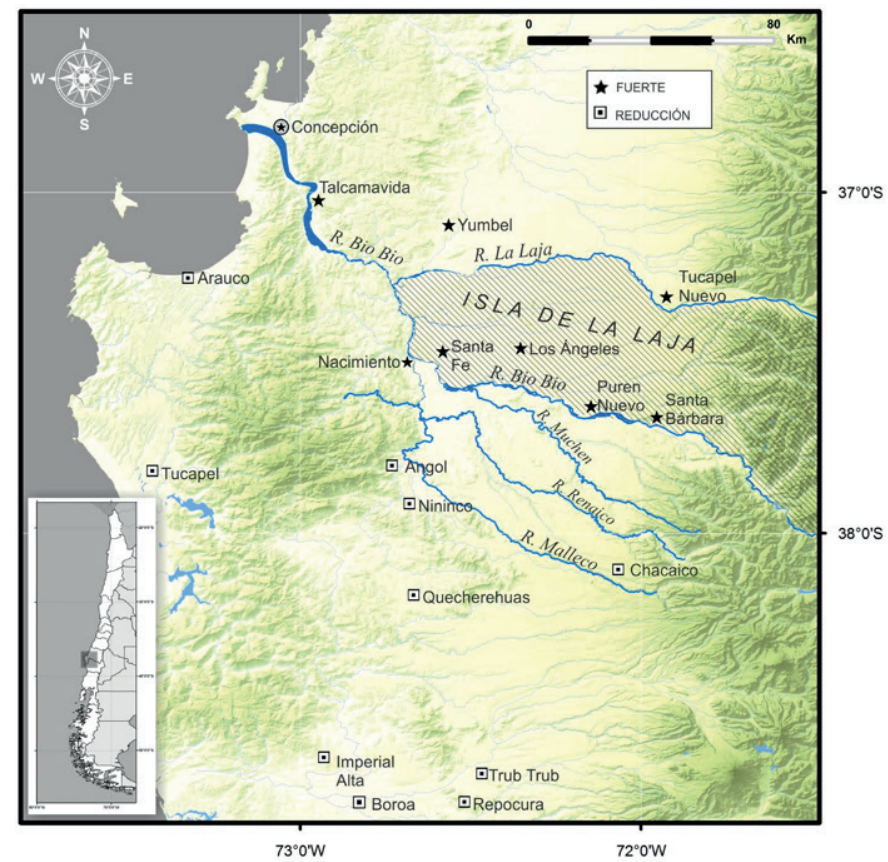

Mapa del sur de Chile

[...] los españoles estancieros que entran con arrias continuas de vino, y emborrachan y desnudan á los indios, comprándolos con este cebo del vino sus hijos, hijas y criados [...]; y estuviera mejor á los misioneros pelear con todos los diablos del infierno que con estos de la tierra"; [eso sin negar parte de la culpa a los propios nativos, puesto que] tambien estorban el fruto la bárbara soberbia de estos indios, la poligamia de los caciques, las borracheras, la ociosidad, los machitunes y la falta de todas leyes (Covarrubias [1708]: 1846: 280).

Parecido razonamiento hacía poco después el padre Bernardo Bell, quien veía como una de las principales dificultades para la evangelización la afición de los indios por "la embriaguez, que no tienen otro gusto ni entertenimiento mayor que sus bebiendas, chicha, vino y todo lo que embriaga"; pero sin que ayudaran a remediarlo "los malos ejemplos que ven en los españoles o mestizos, que viven entre ellos, pues en lugar de cuidar o quitar sus vicios los fomentan, o ya embriagándose con ellos, o trayendo para que se embriaguen y cogiendo mujeres a la usanza como si fueran indios" (Bernardo Bell, junio de 1717, en Foërster, 1996: 311-312).

Los franciscanos llegaron a Chile tempranamente, a comienzos de la conquista del territorio (Pinto Rodríguez, 1990: 102); desde el principio vieron con malos ojos la propensión de los indígenas de la región a reunirse bajo los auspicios de las bebidas embriagantes. Ya a inicios del siglo XVII, fray Pedro de Sosa relacionaba -no sin razón- la costumbre de desposar muchas mujeres y la consiguiente disponibilidad, por parte de los varones, de la mano de obra femenina para elaborar bebidas fermentadas, con la posibilidad de brindar festines:

No estiman oro ni plata ni otra riqueza si no es las mujeres. Cásanse con todas las que pueden alcanzar, porque son éstas las que principalmente trabajan y los sustentan en su vida ociosa que apetecen, y son caudal para las borracheras, fragua de adulterios y deshonestidades (Sosa, [1616] 1898: 177). 
Desde el punto de vista misionero, tan grave como la violación a la monogamia indicada por el cristianismo era que esa misma "sed de mujeres" fuera un motor para la guerra a los españoles, pues de ella podrían obtener cautivas españolas utilizadas con el mismo fin (Sosa, [s.d.] 1898: 202). ${ }^{5}$

Durante el siglo siguiente, el peso de los franciscanos en la labor misional del Reino chileno fue cada vez mayor; luego de la expulsión de los jesuitas en 1767 su presencia se hizo hegemónica (Pinto Rodríguez, 1990). En esa época, y a pesar de una buena cantidad de cambios que habían sucedido entretanto, la opinión de los referentes franciscanos no distaba mucho de la de sus viejos antecesores. Fray Benito Delgado juzgaba que los vicios principales de los indios eran la lujuria, la poligamia y la embriaguez, de manera que "el maior Señor, y mas rico [es] èl q.e tiene mas Mugeres". Todo ello estaba apoyado en el conjunto de costumbres denominado en lengua local admapu, una legislación consuetudinaria que todos debían respetar, y que mandaba "primero: la Poligamia, [y] segundo la Embriaguez". ${ }^{6}$

La vinculación entre embriaguez, poliginia y desorden político conformaba un conjunto letal para las aspiraciones de conversión que los seráficos padres conservaban para con los indios. La poliginia representaba, sin duda, una grave afrenta a las exigencias monogámicas del culto cristiano y era de por sí una costumbre condenable; pero lo era más aún porque se insertaba con coherencia en un modo de vivir diferente del propio y en cierta medida posibilitaba su existencia y reproducción. En el Parlamento de Yumbel de 1692, el cacique Guenchunahuel de Calbuco puso el siguiente reparo:

[...] que en la lei catholica no se admitia mas que una muger y que en la que ellos bivian multipliçidad dellas; pues sera el continuo bivir de su usança y mantenerlos las mugeres de chicha y bestuario en que fundavan su grandeça y obstentaçion (Parlamento de San Carlos de Austria, Yumbel, de 1692, en Zavala Cepeda, 2015: 176-77).

Quien mejor caracterizó la importancia de la bebida en la sociedad mapuche de fines del siglo XVIII, dejándonos a la vez por escrito sus detalladas impresiones sobre el asunto, fue fray Ramón Redrado. Escribiendo en la década de 1770, el franciscano consideraba que los indios hacían de las "verdades" católicas "asunto de Risa en sus Juntas, y cahuines". Redrado pensaba que el esfuerzo y la paciencia de los mensajeros evangélicos podría hacer efecto si no fuera por dos inconvenientes que constituían "la raiz, y principio de donde naze su vida bestial, y las puertas que cierran el paso â su verdadera conversion". 7 Estos eran la "borrachera", es decir los cahuines o festines y el hecho de que los indios no estuvieran reducidos a Pueblos, y se resistieran a cualquier intento de avencindarlos.

Para el Padre los indios no bebían por "solo socorrer la necesidad, y saciar la sed" sino que, habiendo bebida, "no se sacia[n] hasta que se embriaga[n]", con un ansia tan desatada que si pudieran "estar siempre ardiendo en el fuego de la Gula, y torpeza", así lo harían. Es por eso que su "inclinacion innata â la Embriaguez los ha hecho industriosos, y aplicados â Sacar chicha de casi todos los frutos, y frutas de sus tierras". ${ }^{8}$ En efecto, no había prácticamente vegetal que fermentara produciendo alcohol que los nativos perdonasen, ya fueran plantas autóctonas o provenientes del Viejo Mundo e introducidas por los europeos. Redrado enumera: manzana, maíz, cebada, maque, muday, trigo, hiugán, litri, quinoa, papas; y agrega que "âpenas hay fruto Silvestre,
5. En esta época signada por la guerra una de las funciones principales de las juntas estaba vinculada a lo militar, pues la bebida y los rituales acompañaban las decisiones sobre la guerra y los festejos por las victorias (Boccara, 2009: 142-170). Contreras Cruces se sorprende entonces de que en Santiago las "borracheras se representaban como juergas apolíticas y pobremente influenciadas por las religiones nativas, asociándose a la disolución moral y a los excesos indígenas. Tampoco se concebían como espacios de resistencia o de confabulación [...] a pesar de que los castellanos [...] sabían que en ese contexto lo que ellos llamaban borracheras eran grandes reuniones en las cuales jefes, guerreros y machis se preparaban para la batalla o celebraban la victoria. Ellas incluían actos rituales, bárbaros a los ojos hispanos pero de indudable sentido simbólico: como eran el hacer predicciones a partir del análisis de las vísceras de un animal sacrificado, o ejecutar a un prisionero y, junto a la música y las reuniones entre los líderes militares que se sucedían durante el festejo, no faltaban la chicha $u$ otras bebidas alcohólicas. Eran, por lo tanto, el antecedente más directo para sospechar de un ataque" (Contreras Cruces, 2018: 90).

6. ACPFCh, Carpeta 2, f. 12v. Fr. Benito Delgado, "Misiones entre los Yndios de Chile”. Chillán, 1764 aprox.

7. ACPFCh, Carpeta 3, f. 253r. Ramón Redrado, "Relacion de los Yndios de la dos Jurisdiciones de Chile y de Valdivia y de sus Inclinaciones errores, y costumbres", Misión de Arauco, 10/5/1775.

8. ACPFCh, Carpeta 3, f. 253r. Ramón Redrado, "Relacion de los Yndios...", Misión de Arauco, 10/5/1775. 
9. ACPFCh, Carpeta 3, f. 253r. Ramón Redrado, "Relacion de los Yndios...", Misión de Arauco, 10/5/1775. Efectivamente, esas y más plantas eran usadas para elaborar bebidas alcohólicas: ver una lista en Pardo (2004).

10. ACPFCh, Carpeta 3, f. 253 r. Ramón Redrado, "Relacion de los Yndios...", Misión de Arauco, 10/5/1775.

11. ACPFCh, Carpeta 3, f. $253 \mathrm{r}-253 \mathrm{~V}$. Ramón Redrado, "Relacion de los Yndios...", Misión de Arauco, 10/5/1775.

12. En la actualidad, el vino y la chicha también tienen significados simbólicos y modos de uso social diferentes entre los mapuche contemporáneos; ver un estudio etnográfico en Course (2013). ô de cultivo del q. ${ }^{\text {e }}$ no saquen Bebida suficientemente virtuosa, y activa para embriagarlos". ${ }^{\prime}$

Aunque tratase la costumbre de beber como un vicio, Redrado sabía, sin embargo, que no se trataba de una inclinación individual; la bebida tenía una importancia sociopolítica indudable en el contexto de la vida autónoma indígena. Cualquier reunión colectiva, cualquier evento en que hubiera que juntar personas para aportar fuerza de trabajo, servicio militar, apoyo moral, necesitaba de la bebida como elemento aglutinador:

No hay Junta Gral, ni particular, si primero no se haze la Provision de la chicha. Si alguno ha de hazer casa, ô se ha de sembrar alguna cosa, primero previene muchos Meñues, ô tinajas de chicha: despues avisa à los Yndios de su Parcialidad, vienen â ayudarle en la faena de sembrar, ô de levantar su rancho, y concluido el trabajo entra la Funcion de su Cahuiñ, estan bebiendo de dia y de noche mientras dura el caldo de las Botijas. ${ }^{10}$

Redrado no vacilaba en adjudicar al alcohol la incapacidad de los indios para comprender a Dios, recibir la palabra y convertirse a la verdadera fe. Teniendo alcohol y pudiendo organizar fiestas, los indios no estaban dispuestos a asistir a las misas ni a obedecer las normas de conducta que pretendían imponer los misioneros. ${ }^{11}$

Esas costumbres representaban además un costo para los españoles. El obispo Marán se quejó de que tanto los jefes políticos -a la hora de los parlamentoscomo los misioneros -en sus intentos de reunir a los indios para la misa- tuvieran que echar mano del vino como señuelo:

[...] los misioneros entre los agasajos quehacen a sus indios para atraerlos a la misa y al rezo, el principal es el vino. Experimentándose frecuentemente que faltándoles este adictivo, no concurren a la instrucción por más que los solicite el capitán (Marán, 1784 en Hanisch 1990: 136).

Además de las chichas elaboradas localmente desde tiempos pre-coloniales, los indios adoptaron luego el vino traído por los europeos. Este tenía la ventaja de poder conservarse durante más tiempo por su mayor graduación alcohólica, mientras que las chichas deben ser consumidas en muy pocos días. Hay quien piensa que el vino y la chicha tenían cualidades simbólicas diferentes: uno -el vino, importado- expresaba la buena relación con el español extranjero, y era fundamental en los parlamentos y las paces; la otra, de origen local, representaba lo masculino y lo autóctono, y era infaltable en las juntas de guerra y las rebeliones (Zavala Cepeda, 2008: 235-236). ${ }^{12}$ En los parlamentos organizados por las autoridades españolas de la frontera, la posibilidad de ofrecer vino en abundancia garantizaba la presencia de una gran cantidad de indígenas; el vino, uno de los principales gastos de la Real Hacienda en esas ocasiones, además de asegurar la embriaguez de los participantes nativos, que espantaba a los agentes coloniales, servía simbólicamente para sellar los pactos hispanoindígenas (Méndez Beltrán, 1982: 150-153).

La visión negativa respecto del uso indígena del alcohol era compartida por los cronistas laicos que escribieron sobre los temas de la frontera. Cosme Bueno, por ejemplo, consideraba que los indios eran en general "inclinadísimo[s] a la bebida", que de tener vino a mano "están ebrios continuamente", y a falta de vino usaban la chicha local que hacían "de varias frutas; pero en especial i en abundancia de manzanas, de que hai bosques enteros". Bueno coincidía en 
la lectura sobre el peligro político de las bebidas: el tiempo de la chicha era el de los posibles levantamientos contra los españoles, y mientras durase "esta cosecha, que es de enero hasta julio, es el tiempo de sus mayores revoluciones e inquietudes" (Bueno, [1777] 1876: 312). Pedro Martínez de Bernabé consideraba que los indios eran "tan entregados" a la chicha de manzana "que solo cesan de beberla cuando duermen su borrachera [...] i no piensan ni aun en comer mientras hai esta bebida que les sirve de alimento" (Martínez de Bernabé, [1782] 1898: 118-119); sin embargo, agregaba que cuando concluía la época de la manzana comenzaba la del maíz, de la cual hacían la chicha clásica de la tradición andina. ${ }^{13}$

El sabio jesuita Juan Ignacio Molina, quien destacaba la frugalidad de los indios en su mesa cotidiana, notaba que todo cambiaba en los convites, ocasiones en que se reunían unas 300 personas y se consumían "más animales, más granos y más licores que aquellos que podria necesitar una famila entera para sustentarse dos años" (Molina, [1787] 1795: 122). ${ }^{14}$ Su compañero de orden, Felipe Gómez de Vidaurre, también discurrió sobre las ocasiones en que "como son amícismos de gloria y desosisimos de parecer grandes en el mundo, se hacen mutuamente y en especial en tiempo de las cosechas, convites suntuosos". En esas ocasiones en que tratan "sus grandes negocios" sobreviene el dispendio, "nada se ahorra y todo se desperdicia", se sacrifican y comen diversos animales, y el vino

[...] que compran de los españoles, la cidra o chicha, que hacen de las manzanas, o los licores que destilan de tantas otras frutas del país, se presentan a todo en todo el tiempo que dura el convite, que suelen llegar hasta quince dias. Durante este divertimiento, así los hombres como las mujeres, están cuasi siempre borrachos (Gómez de Vidaurre, [1789] 1889: 342).

Gómez de Vidaurre repite el lugar común de otros religiosos: las borracheras implican un descontrol que hace que los padres se olviden hasta de sus hijos, y "las madres, borrachas por muchos dias consecutivos, dejan de dar la leche a sus criaturas, que perecen por falta de alimento" (Gómez de Vidaurre, [1789] 1889: 342$).{ }^{15}$

\section{Prohibiciones y condenas}

Esta perspectiva del asunto llevó a que, como había sucedido en otras partes del Imperio hispano en América, se prohibiera a los españoles la venta de alcohol a los indígenas, con la intención de no atizar el fuego del desorden, el pecado y la rebelión.

A medida que se fue apagando la guerra, el comercio interétnico comenzó a florecer cada vez más y, a pesar de la prohibición general, sin duda el vino tenía su lugar en los intercambios. En el parlamento de Purén de 1698, los indios pedían respecto del comercio: "con los Españoles de Sus ropas, ganados y Comidas, que Se pusiese una medida grande al Vino que Con esso estarian Contentos" (Parlamento de San Juan de Purén de 1698, en Zavala Cepeda, 2015: 211).

Pero el manejo del tráfico también tenía sus riesgos. El levantamiento de 1723 tuvo lugar en gran medida por los abusos de los españoles en tierra de indios: Villalobos (2002) considera que el vino y el aguardiente eran un objetivo principal para los indios en el comercio, y atribuye la rebelión a los abusos de los
13. Véase su descripción del proceso de elaboración de ambas bebidas fermentadas en Martínez de Bernabé ([1782] 1898).

14. Molina distingue los cahuines del mingaco, costumbre de larga tradición andina, "aquellas comidas que acostumbran hacer cuando quieren cultivar la tierra, sembrar los granos, hacer una casa ó cualquiera otra obra que requiera los esfuerzos combinados de mucha gente" (Molina, [1787] 1795: 123).

15. Algo parecido afirmó algo más tarde el franciscano Melchor Martínez ([1805] 1944: 44). 
16. El misionero jesuitas de Santa Fe, Juan Bautista Fertel, se lamentó en esa ocasión de que "los misioneros siembran lágrimas y los españoles cepas. Las sublevaciones, que desde la Conquista de estos indios hubieron, incluso la última del año 22, se originaron todas por el comercio de vino, por el cual, fuera de los vicios que indispensablemente trae consigo la embriaguez, reciben los indios en sus haciendas los mayores daños y agravios de parte de los españoles, motivo de verse obligados a romper cinchas y sacudir el yugo" (en Föerster 1996: 333-334), relacionando nuevamente vino, ofensas españolas y rebeliones indígenas.

17. Además para los misioneros, acostumbrados a ver en la evitación de los placeres -incluyendo la comida, la bebida y el sexo- una vía de llegar a Dios, las borracheras eran justo todo lo contrario de lo que debía hacer un buen cristiano (Pinto Rodríguez, 1991; Salinas, 1991). conchavadores en el comercio del vino. Esos desórdenes -incluidos los derivados de la apropiación de niños, de lo que hablaremos más adelante- fueron los que intentó regularizar el parlamento subsiguiente de 1726, que prohibió la internación de comerciantes cristianos al sur del Bío-Bío.

La Constitución IV del Sínodo de la Iglesia Católica hecho en Concepción en 1744 versaba "sobre la prohibición del comercio de vinos en la tierra adentro", y basándose en las Leyes de Indias, que mandaban que en los pueblos de indios no debía venderse alcohol, argumentaba que con más razón debía aplicarse esto a los indios de tierra adentro, porque en ese caso los "graves inconvenientes que de tal introduccion resultan [en ellos]" se volvían más perniciosos, "así por los agravios comunes del comercio, como por los particulares de esta especie [el vino]". Por ello mandaban

[...] que sin perjuicio de las ordenes de los señores gobernadores, que sin duda cooperarán a impedir dicho comercio de vino, se prohiba so pena de excomunion mayor; por ser el nutrimento de las embriagueces, incontinencias, alteraciones, i demas insultos de los indios, esceptuandose solo aquel, que se deliberare para los parlamentos, i congresos de estados en bien comun de la tierra. (Iglesia Católica, [1744] 1867: 48)

Para los religiosos, el ingreso de los conchavadores españoles a la tierra de indios era el origen de los desórdenes que impedían la propagación de la fe y la obediencia al rey:

[...] la entrada en la tierra de los indios por los españoles con el destino de su comercio, las mas veces clandestinamente, o con tolerancia, i disimulo de algunos cabos subalternos, es la raíz de los agravios, i vejaciones de dichos indios, por las que en parte se impide la propagacion evanjélica, i subordinacion al soberano. (Iglesia Católica, [1744] 1867: 48). ${ }^{16}$

El Sínodo pedia que se respete lo estipulado en el parlamento general de 1726, en el cual se prohibieron las entradas de comerciantes españoles, fijándose unas pocas ferias al año en los pueblos de frontera (Iglesia Católica, [1744] 1867: 46). Para entender la actitud de los misioneros y sacerdotes cristianos respecto de las costumbres nativas debe tenerse en cuenta que portaban una ideología religiosa excluyente (Pinto Rodríguez, 1990 y 1991) e incompatible con los cultos locales, que debían ser borrados y olvidados. La fuerza que movía a los misioneros era la conversión, que implicaba mostrar a los neófitos la verdad de Cristo esperando que la aceptaran por la evidencia de su verdad y de las ventajas de conocerla. Si los nativos debían olvidar sus dioses y objetos de culto, también debían abandonar cualquier modo de vida que los alejase de lo que estaba prescripto para los buenos cristianos. ${ }^{17}$ Pero justamente ese profundo cambio de costumbres era lo más costoso en Chile, quizá los indios tuvieran menos inconveniente en aceptar la idea del Dios cristiano y los demás dogmas que en resignarse a las transformaciones de la vida práctica que los misioneros requerían: reducción a pueblos, renuncia a la poliginia, abandono de las prácticas previstas por el admapu, como la vendetta o la organización de cahuines.

En ese contexto, los franciscanos se distinguieron de los jesuitas en que su objetivo último era la conversión de los indios y no se conformaban con bautizarlos para salvar sus almas. Sin embargo, al llegar la década de 1790 ellos también cambiaron de opinión. Para entender el giro de todos los actores es necesario conocer la situación económica de la frontera del Penco; de allí, y de 
otras condiciones ideológicas, surgió un cambio de política de las autoridades del Reino que repercutió con fuerza en la frontera.

\section{El comercio interétnico en la frontera penquista: subordinación regional, ahogo económico y venta de vino a los indios}

Durante todo el siglo XVIII, y especialmente en su segunda mitad, los poblados de la frontera del Bío-Bío enfrentaban un ahogo económico y financiero dentro del esquema del imperio. El comercio exterior de Concepción se mantuvo en un notable estancamiento durante todo la centuria: entre 1730 y 1779 su valor promedio registró una expansión anual de sólo 0,12\% (Carmagnani, [1973] 2001: 129). Además, durante ese lapso, el comercio cambió en su estructura interna: las exportaciones pasaron de consistir mayoritariamente en productos derivados del ganado a componerse, en gran medida, de productos agrícolas, especialmente trigo, como ocurrió en general en todo el Reino (Téllez Lúgaro et al., 2015). También hubo una expansión en las exportaciones de vino, que pasaron de 828 botijas en 1751 a 4.630 en 1778 (Carmagnani, [1973] 2001: 132), sin dar por eso salida a la abundante producción local.

Dentro del sistema económico vigente en el frente del Pacífico los pobladores de la frontera se hallaban completamente subordinados a la voluntad de los hacendados y los comerciantes del Valle Central y de Santiago, dispuestos a mantener su vinculación privilegiada con Lima. ${ }^{18}$ Las producciones locales no alcanzaban a cubrir los altos costos de las mercancías importadas desde Lima o Santiago (Solano, [1780] 1994: 142). Ante la crónica escasez de metálico (Romano, 1965) y de salida para las mercaderías locales, como vino y aguardiente, trigo y ganados, los españoles sureños se volcaron con singular vocación al comercio con los indios que tan cerca tenían, y que además de una amenaza suponían una salida del atolladero económico en que los encerraba el sistema colonial.

Durante toda la centuria, el comercio interétnico en la frontera del Bío-Bío fue moneda de la más común. Tanto los indios cruzaban a tierras cristianas para comerciar en los poblados, como los conchavadores españoles hacían lo propio internándose en territorios indígenas más allá del río. El floreciente comercio fronterizo consistía, en general, en que los indios compraban animales -caballos y vacunos- a cambio de sus ponchos (León Solís, 1991: 88-93, 113; Alioto y Jiménez, 2010). Para los españoles, una de las mayores ventajas de este comercio era que se hacía bajo la forma del trueque, y por lo tanto no implicaba la erogación de moneda.

Este intercambio fue visto por las autoridades, sobre todo alrededor de mediados de siglo, como algo extremadamente perjudicial para los intereses coloniales por la sangría de caballos, fundamentales para la guerra. Una adicional preocupación venía dada por la introducción de vino que, se creía, echaba leña al fuego de la rebelión y la guerra que los nativos siempre mantenían encendido.

El rubro fundamental que todo conchavador español buscaba y pagaba bien eran los ponchos de la tierra, tejidos pacientemente por las mujeres indias, y uno de los motivos por los cuales el matrimonio poligínico daba a quienes lo practicaran buenas posibilidades económicas. Los ponchos eran cambiados en tierra de indios y en tierra de cristianos; por ellos estos últimos trocaban vacas, caballos, mulas, ovejas, trigo, estribos y otros elementos del apero, herramientas de
18. En realidad, todo el Reino de Chile tenía dificultades mercantiles dentro del esquema económico español. Las mercancías chilenas no podían colocarse en España por el costo de los fletes y las reducidas exportaciones al Perú no alcanzaban a pagar los productos importados, generando un fuerte déficit en la balanza comercial (Villalobos, [1968] 2009: 188-196). 
19. BNC, MM, tomo 194, fs. 296-297. Oficio de Manuel de Amat al Rey, s. f.

20. BNC, MM, tomo 189 , fs. $140-$ 140v. Manuel de Amat al Rey, "El Presidente [...] en punto de Comercio de vino y de ganados con los Yndios de la tierra adentro", 16/3/1759. metal y armas. Esos tejidos podían luego ser exportados (Solano, [1756] 1995: 188) y mientras los precios que se pagaban en Concepción y Talcahuano por los productos agropecuarios locales eran muy pobres, los ponchos se revendían luego a buen precio.

En los distintos fuertes fronterizos salían por año más de dos mil indígenas a comerciar y a trabajar en las estancias (Solano, [1756] 1995: 208-237), a lo que habría que sumar los conchavadores españoles que se internaban en territorio nativo. Este comercio se había llevado adelante a pesar de la prohibición vigente, sin duda desatendida. El volumen del tráfico era considerable; Carvallo calculaba que el obispado de Concepción vendía “30 a 40 mil pesos en ganados vacuno, caballar i de lana, trigo, vino, fierro i cobre labrado" a cambio de 30 mil ponchos y 5 mil fanegas de sal (Carvallo y Goyeneche, 1876: 94).

La ilusión de algunas de las autoridades coloniales era revertir el sentido inadecuado del tráfico. La clave para ello, según siempre se había creído, era prohibir el comercio de los ponchos, principal bien adquirido de los indios por el aprecio que se le tenía como prenda de vestir en el mundo rural colonial, además del resto de los elementos prohibidos que incluían caballos, armas blancas y de fuego y otros elementos de metal. Hacia mediados de siglo muchos pensaban que con cortar del todo el comercio los indios se subordinarían rápidamente, porque el tráfico con los españoles los había hecho dependientes.

Para una nueva y crecientemente influyente parte de la burocracia colonial la manera correcta de lograr la inversión del flujo, más que en la prohibición, estribaba en incentivar la venta de vino a los indios. En la mentalidad de estos funcionarios, los nativos habrían dado cualquier cosa con tal de conseguir vino; además de animales y armas los propios hijos de los indígenas podían cambiar de manos hacia el lado español. Manuel de Amat, presidente de Chile desde 1755 y precursor de esta línea de pensamiento que otros funcionarios de la Corona tardarían mucho más en procesar, argumentaba:

[...] pues con prohibir el uso de los ponchos con que estos comercian con nosotros, y dar libertad á los españoles para que les entren con franqueza el vino en cuatro años, se les quitavan sus ganados, todas las armas blancas que hoy poseen por sus comercios [...] y aun los hijos hasiendo de ellos lo que se tubiere por mas conveniente. ${ }^{19}$

En efecto, el objetivo era recuperar los animales vendidos durante tantos años y de este modo deshacer el poder militar indígena. Dando permiso para introducir vinos además

[...] se le daría consumo, y valor a una especie que su propria abundancia, la ha hecho poco apreciable en la frontera. Y á corto tiempo podria ser, que á falta de Ponchos nos cambiasen los mismos ganados que nos han llevado, dexandolos de esta suerte mas necesitados y dependientes y menos armados y poderosos. ${ }^{20}$

El comercio de vino estaba prohibido, como el de ganados, lo que hacía que sólo quienes tenían contactos con las autoridades pudieran llevarlo a cabo "con conocido beneficio", llevando la mercancía impunemente a tierra de indios. La idea era anular la prohibición, derribando la oclusión que impedía a los pequeños conchavadores internarse libremente en territorio indígena con sus mercaderías. Gracias a la venta libre de vino a los nativos los gobernantes pensaban atraerlos hacia el buen trato con los españoles, y sobre todo desviarlos 
del tráfico de ganado y armas; para ellos, la sed de vino entre los indios se suponía tan grande que, eventualmente, terminarían por vender todo lo que tenían, incluyendo sus planteles ganaderos.

\section{La iniciativa del libre comercio en la década de $\mathbf{1 7 9 0}$}

En 1793, el Capitán General del Reino Ambrosio Higgins llamó a un nuevo Parlamento general, que tuvo lugar en Negrete. Uno de los puntos relevantes que Higgins acordó con los cuatro vutanmapus de la Araucanía fue que en adelante el gobierno español promovería con todas sus fuerzas el comercio libre entre indios y españoles, como medio principalísimo para estrechar los contactos pacíficos y olvidar las antiguas guerras que caracterizaron las relaciones interétnicas en Chile durante tanto tiempo. De esta manera Higgins se embarcaba en una corriente que nacía, en gran medida, de la propia debilidad de las armas españolas, incapaces de someter a los grupos fronterizos hostiles y provocadoras de grandes gastos que la Real Hacienda ya no quería sufragar (Weber, 2005: 181).

Para Higgins, resultaba imprescindible que el comercio fronterizo cambiase de sentido. Había llegado el tiempo de modificar las disposiciones prohibitivas que laceraban los intereses de casi todos los protagonistas de la economía de la frontera del Bío-Bío. Las ventajas eran indudables:

Toda la Provincia de la concepcion tomarà un nuevo semblante de prosperidad [...] sus vecinos han gemido hasta ahora en secreto por el cruel sistema de la prohivision del Comercio con los Yndios. Lleno aquellos de los frutos que les ministra la feracidad de este terreno: sus adelantamientos han sido y son necesariamente lentos y escasos por falta de puntos a donde transportarlos para su expendio. Lima a penas consume los que le ofrecen los Partidos mas fertiles y mas cercanos del Obispado de Santiago y dexa à estos por necesidad en la inaccion. Si los vecinos de la Provincia de Concepcion huviesen podido negociar abiertamente con los Yndios desde cincuenta años a esta parte en que se hecharon las primeras travas à su trato todo esto estarì mas adelantado. ${ }^{21}$

Como vimos, la región de Concepción permanecía bajo un ahogo financiero y económico de cuya firme presión parecía difícil hallar un respiro. La producción de vino, ganado y otros bienes no podía colocarse satisfactoriamente en el mercado. Así como los ganaderos de la región, por su mano o por medio de los conchavadores, siempre vendieron ganado a los indios, el vino también había sido introducido a la tierra de manera consuetudinaria. Pero la liberalización comercial prometía mejores tratos y mayor cantidad de litros trocados, y sobre todo la oportunidad de abrir la oferta para que los productores pecuarios y vinícolas, y los traficantes que no estaban acomodados con los comandantes fronterizos pudieran igualmente entrar en el trato.

Una vez aprobada la propuesta de Higgins por la Corona, ${ }^{22}$ reconociéndose de este modo que las antiguas leyes prohibitivas del comercio fronterizo no tenían ya sentido ni utilidad y por lo tanto que el tráfico debía ser legalizado y liberalizado, don Ambrosio decidió consultar a los sectores más interesados y destacados de la frontera. Se proponía averiguar en primer término cuáles serían las mejores disposiciones regulatorias del comercio, y a partir de ellas formar un nuevo reglamento que asegurara contactos pacíficos y fructíferos para los españoles.
21. BNC, MM, tomo 330, f. 99. "Copia de varios capitulos que tratan sobre el comercio con los Yndios de la representacion con que el Exmô Señor d. Ambrosio Higgins Vallenar dirigio à S.M. por la via respectiva el Parlamento general celebrado en Negrete en el año de 1793, y se aprovó en Real Orden de 7 de Diciembre de 1793", en "Expediente relativo al comercio general con los Yndios de la frontera".
22. La aprobación fue en realidad tácita y Higgins la tomó como tal, a pesar de que la respuesta del rey no hace mención específica a la cuestión de la apertura comercial. 
23. BNC, MM, tomo 330, fs. 103-105. "Copia de varios capítulos que tratan sobre...", en "Expediente relativo al...".

24. BNC, MM, tomo 330, f. 153. Informe del dictamen del Cabildo Eclesiástico al Gobernador Intendente, Concepción, 23 de septiembre de 1794, en "Expediente relativo al...".

25. Esto guarda relación con la creciente desconfianza de la élite colonial respecto de la plebe criolla y mestiza, especialmente la rural; (Continúa en página 139).

26. BNC, MM, tomo 330, f. 195. Copia del oficio de Pedro Nolasco del Rio al Gobernador Intendente Francisco de la Mata Linares, Los Ángeles, 27 de agosto de 1790 , en "Expediente relativo al...".

27. BNC, MM, tomo 330, f. 216. Dictamen del Provincial de San Francisco Fr. Lorenzo Núñez dirigido al Capitán General Ambrosio Higgins, Santiago de Chile, 22 de noviembre de 1795 , en "Expediente relativo al...".

28. BNC, MM, tomo 330, f. 196. Copia del oficio de Pedro Nolasco del Rio [...], Los Ángeles, 27 de agosto de 1790 , en "Expediente relativo al...".

29. BNC, MM, tomo 330, f. 196. Copia del oficio de Pedro Nolasco del Rio [...], Los Ángeles, 27 de agosto de 1790 , en "Expediente relativo al comercio...".
El obispo de Concepción, el Cabildo Eclesiástico y el Cabildo civil, los vecinos de la ciudad congregados en un Cabildo abierto, el provincial franciscano y finalmente el Gobernador Intendente de la provincia debieron dar sus opiniones respecto a diez puntos relativos al tráfico, que incluían: 1) si debía limitárselo a lugares y tiempos determinados, o 2) si debía ser libre, 3) si debía haber puntos señalados para la entrada y la salida de la tierra, 4) si para internarse en la tierra debía presentarse una guía de la aduana a los comandantes correspondientes, 5) las cantidades de vino a introducir, 6) los medios para que los conchavadores actuaran de buena fe, 7) premios para incentivar su actividad en caso de sacar muchos caballos, 8) si debía prohibirse el tráfico de instrumentos de fierro, 9) si las mercaderías deberían ser exceptuadas de derechos, y 10) cómo evitar que se formaran monopolios y se exigieran derechos al tránsito. ${ }^{23}$

Las respuestas muestran una gran coherencia: la iniciativa fue recibida casi unánimemente como una bendición. Hasta el obispo de Concepción, cuyos antecesores siempre se habían quejado con amargura del conchavo, se mostraba afecto a una liberalidad imprevista.

Entre los argumentos con los que se defendió la liberalización general del comercio, y especialmente la del vino, el más destacado fue tal vez, como vimos que lo anticipara Higgins, el de las ventajas que ello reportaría para los productores de la provincia. El Cabildo Eclesiástico mostraba que el vino era el item principal del comercio "siendo constante que si se huviese de negar el trafico de esta especie, que es la que mas abunda en el Obispado", el intercambio de los demás frutos de la tierra "serìa tan reducido, que antes de mucho tiempo vendrìa a quedar en nada". ${ }^{24}$

Además, de ser liberado el comercio, se terminaría con los malos conchavadores y sus prácticas ilícitas, pues eran quienes con sus perfidias alteraban a los indios. Pedro Nolasco los calificaba como "la gente mas soez, y despreciable del Reino"; ${ }^{25}$ para él esos comerciantes internados entre los indios eran peligrosos para la paz pública porque con tal de tener

[...] buena acogida con los Yndios para que no los delaten, ó les quiten quanto llevan, como suele suceder por sus iniquidades, y fraudulencias, les persuaden mil novedades opuestas á los medios pacificos con que se pretenden conservar, y muchas veces son causa de revoluciones y alborotos que aunque no pasen á excesos contra nosotros, siempre son temibles. ${ }^{26}$

Había quien argumentaba que si se franquease el paso a todos los comerciantes que quisieran hacerlo, personas de mejor calidad se animarían a internarse para ejercer ese tráfico, ${ }^{27}$ otros, como Nolasco, pensaban que los conchavadores nunca serían honrados porque "ninguno de esta clase se expondrá a los riesgos que trae consigo el trato de los Yndios en sus propias tierras". ${ }^{28}$ Una de las actividades de estos comerciantes que se suponía, con razón, que podía alterar gravemente a los indios era la apropiación y tráfico de niños nativos, vieja práctica de larga duración en la frontera meridional (Villar y Jiménez, 2001; Davies, 2009; Valenzuela Márquez, 2014; Poblete, 2019). Pedro Nolasco, temiendo las mismas consecuencias que las que llevaron al levantamiento de 1723 pensaba que el "desorden del comercio con que arrancaban á los Yndios sus hijos, y haciendas tuvo mucha parte en aquel levantamiento". ${ }^{29}$ En cambio, el franciscano Núñez opinaba que los conchavadores no eran gente dañina, y 
respecto a los párvulos nadie podía "decir con verdad, q.e los Indios hayan dado, ò q.e los conchavadores y comerciantes les hayan robado sus hijos". ${ }^{30}$

De todos modos, la inquietud heredada del pasado relativa a que la introducción de vino podría alborotar a los indios tuvo su peso, ya fuese por los efectos del vino mismo sobre los espíritus, o por las prácticas inicuas de los conchavadores. El Cabildo secular, el más interesado en la liberación por la procedencia de sus integrantes, no se animaba a proponer la libre internación de los conchavadores, y recomendaba en cambio lo siguiente:

\section{Que aunque para el Trafico y expendio de los frutos del Pais y señaladamente de los vinos, le estaria mejor a la Provincia y le seria una conocida ventaja, la internacion ilimitadade estos renglones à las Freiras [sic] Casas y Poblaciones de los mismos Yndios por que asi se facilitarian mas los cambios, y los naturales serian exitados a aquel Trafico; pero considerando, que la licencia indefinida de introducir vinos, podria ocasionar algun desorden en los primeros años de este Comercio; El Cavildo [...] es de parecer que se conceda à los Españoles la livertad absoluta de introducir y vender en las Plazas de la Frontera todos los vinos que quieran [...] para que alli comprenlo los Yndios y lleven a sus Tierras de la Cantidad ilimitada que les parezca. Y que por haora $[\ldots]$ se modere la que hagan los Españoles à la Tierra de los Yndios, de manera que cada uno en cada viaje que haga solo pueda internar ocho cargas del ya expresado renglon de los vinos $=^{31}$}

Todo el mundo sabía que el Sínodo había prohibido la venta y el tráfico de vino a los indios, pero todos también pensaban que esa veda ya era inadecuada e inútil por varios motivos. Uno, que ya comentamos, era que los indios tenían como procurarse sus propias bebidas alcohólicas. Higgins consideraba que cuando no tenían vino lo sustituían por "la Chicha de Mansana y otros brevages fermentados perjudiciales a su salud y no sanos como el vino que en este Pais no es dañoso" ${ }^{32}$ El obispo Marán también sostuvo que para "los efectos q.e puede producir la predicha especie, ay entre los Yndios en abundancia, otras, como la Chicha". ${ }^{33}$ Sólo el Cabildo Eclesiástico parecía no estar del todo convencido de esto. ${ }^{34}$ La opinión mayoritaria coincidía con la que sigue:

Si el fundamento de esta proivicion és como se dice que el vino embriaga á los Yndios, y en este estado meditan ruidos, y alborotos, poseyendo éllos con abundancia otros Licores que tamvien los embriaga, como son la Chicha de Manzana, de Mays, Guigan \&a serán ociosa tamvien para los mismos efectos, y por conseqüencia es inutil la proivicion del Vino sino ay advitrio para embarazarles la borrachera de la Chicha. ${ }^{35}$

Para horadar discursivamente las anteriores políticas de censura y cerrazón se sostuvo que las prohibiciones sólo se habían mantenido porque hubo personas que se beneficiaron de ellas. Higgins echó la culpa a los jesuitas expulsos, quienes habrían promovido aquellas leyes prohibitivas para "hacer ellos exclucivamente su Comercio [según] la voz general de los Havitantes de esta Provincia, y lo dicen hoy con la franqueza q. antes no se atrevieron à explicar". ${ }^{36}$ Por su parte el provincial franciscano Lorenzo Núñez, cuya opinión es la más llamativa por el fervor con que se convirtió al credo del libre comercio, denunció que las prohibiciones sólo se mantenían por las conveniencias de los comandantes de frontera y los capitanes de amigos que, habiendo monopolizado un comercio secreto en provecho propio, no querían competencia:
30. BNC, MM, tomo 330, f. 233. Dictamen del Provincial de San Francisco Fr. Lorenzo Núñez [...], Santiago de Chile, 22 de noviembre de 1795, en "Expediente relativo al...". También explica allí que: "Alguna vez suelen los Indios permutar por los efectos q.e necesitan, ò vender à pagas de Plata, los Parvulos q.e han robado en sus Malócas. Otras, los sacan los Españoles, de los partos clandestinos q.e desampáran sus inhumanas Madres, $Y$ otras finalmente, los sacan de los Indios fronterizos mas miserables con motivo de instruirlos y educarlos: y aun así, los entregan con sobradas limitaciones y condiciones, q.e jamás permiten déxen de cumplirse: siendo la principal la de devolucion, q.e en toda la Frontera ha causado las amarguras q.e son notorias"

31. BNC, MM, tomo 330 , fs. 123-124. Informe del dictamen del Cabildo Secular al Gobernador Intendente, Concepción, s. f., en "Expediente relativo al comercio...”.

32. BNC, MM, tomo 330, f. 100 . “Copia de varios capítulos que tratan sobre...", en "Expediente relativo al comercio...".

33. BNC, MM, tomo 330, f. 113. Informe del dictamen del Obispo de Concepción Francisco José Marán al Gobernador Intendente, Concepción, 8 de julio de 1794, en "Expediente relativo al comercio...”; la misma opinión de Manuel Santa María Escovedo a fs. 191.

34. "No es objecion el decir que ellos no necesitan de este bien para sus corrupciones, teniendo a mano, y por mui familiar la Chicha compuesta, y extrahida de el Zumo de Manzana pues aun quando esto sea asi, siempre es razonable estrechar este Comercio, por la prevision de las fatalidades q.e preparan sus ensanches": BNC, MM, tomo 330, f. 154. Informe del dictamen del Cabildo Eclesiástico [...], Concepción, 23 de septiembre de 1794, en "Expediente relativo al comercio...”.

35. BNC, MM, tomo 330, f. 169. Dictamen de Pedro Nolasco del Río al Gobernador Intendente, Los Angeles, 28 de julio de 1794, en "Expediente relativo al...".

36. BNC, MM, tomo 330, f. 100. "Copia de varios capítulos que tratan sobre...", en "Expediente relativo al...". 
37. BNC, MM, tomo 330, fs. 236-237.. Dictamen del Provincial de San Francisco Fr. Lorenzo Núñez [...], Santiago de Chile, 22 de noviembre de 1795, en "Expediente relativo al..."...Núñez apoyaba su denuncia en un caso concreto: "Pocos años despues de haver yo salido de Superior de la Mision de Araúco, se oyeron de publico varias quexas sobre las entradas de algunos Comerciantes ò conchavadores. Pero fueron por un Comandante q. e en seis meses introduxo à los Indios por su cuenta sobre mil arrobas de vino. [...]q. ${ }^{\mathrm{e}}$ cada momento recelaba y forjaba alborotos, y los achacava al Vino q.e introducían los Españoles, sin acordarse de q. ${ }^{\text {e }}$ su Comercio de esta Especie lo havía hecho exclusivo".

38. BNC, MM, tomo 330, f. 214. Dictamen del Gobernador Intendente Francisco de la Mata Linares dirigido al Presidente y Capitán General Ambrosio Higgins. Concepción, 29 de septiembre de 1794 .

39. BNC, MM, tomo 330, f. 216. Dictamen del Provincial de San Francisco Fr. Lorenzo Núñez [...], Santiago de Chile, 22 de noviembre de 1795 , en "Expediente relativo al...". En este pesimismo coincidía paradójicamente con su rival, el Gobernador Intendente.

40. En la década de 1790 el comandante Amigorena se quejó desde Mendoza de los conchavadores españoles que se internaban desde el lado occidental de la cordillera por varios boquetes a vender vino a los pehuenches; su queja se vinculaba, incluso más que al temor de que el alcohol fuera peligroso, al tránsito incontrolado de personas y bienes por tierras fronterizas (Valenzuela Márquez, 2007).
Poniendose como de necesidad q. los Comandantes no pueden subsistir sin un Comercio ratéro; y que á los Capitanes de amigos se les debe considerar como de igual necesidad la introduccion de algunos efectos para sus subsistencia y para los acostumbrados agasajos, la decantada prohibicion del Comercio de Aguardientes y Vinos produciría necesariamente los efectos q. han producido hasta ahora las prohibiciones y los Decretos Synodales: por q.e Comandantes y Capitanes, q. cuidan muy bien de sus intereses, q. no tienen otro modo ni arbitrio de adelantarlos, y q. saben q. Aguardientes y Vinos son las especies estimables y preferibles, introducirán tanto mas, quanto mas estrecha y apretante fuere la prohibicion. ${ }^{37}$

Otra variante argumental es la del gobernador intendente de Concepción, Francisco de la Mata Linares, quien sostenía que el comercio de estas especies venía haciéndose desde siempre, a pesar de la prohibición, de modo que la iniciativa de liberarlo sólo blanquearía lo que ya ocurría en la práctica. Aunque no estaba de acuerdo en que se permitiera la introducción de vino a los españoles, y creía que debía moderarse la venta a los indios en los pueblos de la frontera, el intendente pensaba que:

[...] aun quando la extraccion fuese ilimitada, no sería mucho maior que la actual, y nunca correspondiente al deseo de los vecinos de Concepcion que se figuran con qualquiera novedad mas facilmente felices de lo que permite su situacion local y política. ${ }^{38}$

Finalmente, se pensaba que el comercio libre y la venta de vinos también serviría para adquirir de los indios ponchos y caballos: este último renglón era fundamental por su importancia militar. Higgins era promotor de esta opción, como lo había sido Amat. Otros no eran tan optimistas; el provincial franciscano, por ejemplo, no creía que los indios fueran a desprenderse de sus caballos:

[...] pero yo dudo que se verifique con estas circunstancias, porque los Indios conocen bien que á pie no son nadie, y asi no se desacen sino de lo muy sobrante, que és poco (porque ellos no tienen grandes crias de la especie) á menos que lo adquieran en alguna maloca. ${ }^{39}$

El plan de desmontar a los indios y anular su condición de jinetes podía ser cuestionado por su falta de realismo, pero eso no inmutó al marqués de Osorno cuya finalidad era menos recuperar el ganado caballar que ofrecer salida a los productores penquistas. Vistas las opiniones, Higgins dictó el Reglamento que, si bien incentivaba la venta de vino a los araucanos, al igual que los anteriores no permitía a los conchavadores ingresar al sur del Bío-Bío para sus negocios y prescribía que el tráfico tuviera lugar en los fuertes de la frontera y bajo la supervisión de sus comandantes. Por testimonios ulteriores sabemos que esta disposición, como era de prever, fue de nulo cumplimiento. ${ }^{40}$

\section{Conclusiones}

Hemos visto aquí las cambiantes opiniones y políticas resultantes respecto del comercio de vino con los indios independientes en la frontera de Chile. Las actitudes variaron de considerar a la bebida como un combustible demoníaco para el libertinaje y la rebelión, cuyo trato por lo tanto debía ser prohibido, a una visión más pragmática. Dicha visión reconocía que los indios tenían sus propias bebidas alcohólicas más allá del vino español; que el comercio de vino había tenido lugar a pesar de las prohibiciones y estatutos legales; y que ese 
mismo comercio, una vez liberado, podía dar salida a una producción local que no encontraba mercado en los centros septentrionales del imperio. Cuando en 1793 Higgins propuso la liberalización del comercio de vino, no hubo voces en disidencia. Una vez madurada la visión borbónica de suplantar las armas por el comercio, en aquellos lugares en que la conquista era imposible y costosa, todos los protagonistas de la frontera la adoptaron como propia, especialmente porque era concordante con las necesidades económicas de la población local.

La liberalización parcial llevada a cabo en la década de 1790 respondió a diversas causas, entre las que se encuentran la debilidad militar española y su necesidad de ahorrar dinero y obtener recursos evitando gastos militares. Y, en relación con ello, también incidió la situación de una región que sufría una crisis de sobreproducción de bienes que no podía colocar en el mercado colonial, cuya posibilidad de comercializar esos bienes -aunque fuera entre los "bárbaros"- era bienvenida ya que, entre otras ventajas, se contaba con que los nativos no exigían el casi inexistente dinero para las transacciones y compraban de buen grado el vino y los animales que los penquistas no podían exportar. Desde la nueva óptica española, a su vez, era mejor vender a los indios vino y no animales -especialmente caballos- que pudieran luego ser utilizados en contra de los vasallos de la corona. Así los viejos pruritos morales y teológicos, sin desaparecer, se desvanecieron dejando lugar a una visión que, aun entre los servidores de Cristo, se atenía mucho más a las prácticas del mundo real.

\section{Notas}

25. paralelamente a las que mencionamos respecto de los indígenas independientes, las autoridades desplegaron una serie de medidas legislativas, políticas y judiciales que tendían a un creciente control social, dirigido contra vagos y ociosos y las conductas que los caracterizaban, entre las que se contaban la borrachera y la frecuentación de las pulperías (Góngora, 1966; Araya Espinoza, 1999). León Solís (2006) interpreta que los afuerinos significaban una amenaza al orden tanto para las autoridades españolas como para los ulmenes mapuche, quienes colaboraron con las primeras en su control. (En página 136). 


\section{Fuentes documentales citadas}

" ACPFCh: Archivo del Colegio Propaganda Fide de Chillán, carpetas 2 y 3 (Santiago de Chile).

» BNC, MM: Biblioteca Nacional de Chile, colección Manuscritos Medina, tomos 189, 194 y 330 (Santiago de Chile).

\section{Q Bibliografía citada}

»Alioto, S. L. y J. F. Jiménez (2010). "Pues para ello les quedaba livertad": comercio e interdependencia en las fronteras meridionales del Imperio español (segunda mitad del siglo XVIII). Barbarói 32: 178-204.

" Araya Espinoza, A. (1999). Ociosos, vagabundos y malentretenidos en Chile colonial. Santiago de Chile, DIBAM/ Lom Ediciones/ Centro de Investigaciones Barros Arana.

"Azevedo Fernandes, J. (2004). Selvagens Bebadieras: Álcool, Embriaguez e Contactos Culturais no Brasil Colonial. Tese de doutoramento. Niterói, Universidade Federal Fluminense. Lugar

» Azevedo Fernandes, J. (2007). Sobriedade e embriaguez: A luta dos soldados de Cristo contra as festas do Tupinanmbás. Tempo: Revista do Departamento de História da UFF 11 (22): 98-121.

»Boccara, G. (2009). Los vencedores. Historia del pueblo mapuche en la época colonial. San Pedro de Atacama, Editorial IIAM/ Ocho Libros Editores.

»Bueno, C. ([1777] 1876). "Descripción de las Provincias del Obispado de Santiago i Concepción" en Colección de Historiadores de Chile y Documentos Relativos la Historia Nacional X: 289-319. Santiago de Chile, Imprenta de la Librería del Mercurio.

" Carmagnani, M. ([1973] 2001). Los mecanismos de la vida económica en una sociedad colonial. Chile 1680-1830. Santiago de Chile, DIBAM.

»Conrad, M. (1999). Disorderly Drinking: Reconsidering Seventeenth-Century Iroquois Alcohol Use. American Indian Quarterly 23 (3/4): 1-11.

" Carvallo y Goyeneche, V. (1876). “Descripcion histórico-jeográfica del Reino de Chile” en Colección de Historiadores de Chile y documentos relativos o a la historia nacional X: 5-209. Santiago de Chile, Imprenta de la Librería del Mercurio.

"Contreras Cruces, H. (2014). Borracheras, huidas y rebeldía entre los indios de Chile colonial. Decretos, autos y bandos de los siglos XVI y XVII. Corpus 4 (1). Disponible en Internet: http://corpusarchivos.revues.org/642. Consultada el: 8 de octubre de 2016.

»Contreras Cruces, H. (2018). "Viviendo entre cristianos como gentiles y entre españoles como bárbaros". Borracheras indígenas, doctrina cristiana y migración forzosa en Chile central, 1575-1655. Revista Complutense de Historia de América 44: 87-109. 
" Corcuera de Mancera, S. (1991). El fraile, el indio y el pulque. Evangelización y embriaguez en la Nueva España (1523-1548). México, Fondo de Cultura Económica (FCE).

" Covarrubias, Antonio ([1708] 1846). “Memorial por via de informe á los señores de la real Junta, que mandó hacer el Rey N.S. para el mayor progreso de las misiones del reino de Chile", en C. Gay; Historia física y política de Chile, Documentos sobre la historia, la estadística y la geografía 1: 273-279. Paris, Imprenta de Maulde y Renon.

»Course, M. (2013). The Apple is Grown, the Grape is Given: Two Modes of Mapuche Exchange. The Journal of Latin American and Caribbean Anthropology 18 (1): 1-13.

»Dailey, R. C. (1968). The Role of Alcohol among North American Indian Tribes as Reported in the Jesuit Relations. Anthropologica NS. 10 (1): 45-59. Disponible en Internet: https:// www.jstor.org/stable/25604758. Consultada el: 15 de diciembre de 2019.

"Davies, G. (2009). “'Rescates o compras' de indígenas en Carmen de Patagones (17951836), un fenómeno particular de mestizaje" en Farberman, J. y S. Ratto (coords.); Historias mestizas. Trayectorias de indígenas, españoles y criollos (siglos XVII a XIX): 115-143. Buenos Aires, Biblos.

»Dietler, M. (2001). "Theorizing the Feast: Rituals of Consumption, Commensal Politics and Power in African Contexts" en Dietler M. y B. Hayden (eds.); Feasts: Archaeological and Ethnographic Perspectives on Food, Politics and Power: 65-114. Washington \& London, Smithsonian Institution Press.

"Dietler, M. (2006). Alcohol: Anthropological/ Archaeological Perspectives. Annual Review of Anthropology 35: 229-249.

"Febrés, A. (1765). Arte de la lengua general del Reyno de Chile con un diálogo chilenohispano muy curioso [...] compuesto por el P. Andres Febre. Lima, calle de la Encarnación.

" Foërster, R. (1995). Introducción a la religiosidad mapuche. Santiago de Chile, Editorial Universitaria.

»Foërster, R. (1996). Jesuitas y mapuches: 1593-1767. Santiago de Chile, Editorial Universitaria.

» Gómez de Vidaurre, F. ([1789] 1889). "Historia geográfica, natural y civil del reino de Chile" en Colección de historiadores de Chile y documentos relativos a la historia nacional XIV y XV. Santiago de Chile, Imprenta Ercilla.

" Góngora, M. (1966). Vagabundaje y sociedad fronteriza en Chile: siglos 17-19. Cuadernos del Centro de Estudios Socioeconómicos 2: 1-41.

" Hanisch, W. (1990). Memorias sobre Misiones Jesuitas de 1784-1785. Historia 25: 103159. (Contiene la: Relación de las misiones del obispado de la Concepción de Chile, de Francisco José [Maran], obispo de la Concepción de Chile. Concepción, 28 de Agosto de 1784).

» Iglesia Católica ([1744] 1867). Primer Sínodo Diocesana [...] en la Santa Iglesia catedral de dicha ciudad de la Concepción. Santiago de Chile, Imprenta del Independiente.

»Jennings, J. (2014). "A Glass for the Gods and a Gift to my Neighbour: the Importance of Alcohol in the Pre-Columbian Andes" en Pierce G. \& A. Toxqui (eds.); Alcohol in Latin America: 25-45. Tucson, The University of Arizona Press.

»León Solís, L. (1991). Maloqueros y conchavadores en Araucanía y las pampas, 1700-1800. Temuco, Ediciones Universidad de la Frontera.

"León Solís, L. (2006). Parlamentos y afuerinos en la frontera mapuche del río Bío-Bío (Chile), 1760-1772. Fronteras de la Historia 11: 87-119. 
» Martínez de Bernabe, P. U. ([1782] 1898). “La verdad en campaña. Relación histórica de la plaza puerto i presidio d Valdivia [...]” en Biblioteca Jeográfica-hidrográfica de Chile, Segunda serie. Santiago de Chile, Imprenta Elzeviriana.

" Martínez, M. ([1805] 1944). La Iglesia y las creencias y costumbres de los Araucanos en Chile. Relaciones de la Sociedad Argentina de Antropología IV (1 a serie): 25-55.

» Méndez Beltrán, L. M. (1982). “La organización de los Parlamentos de Indios en el siglo XVIII” en Villalobos, S.; Aldunate, C.; Zapater, H.; Méndez, L. M. y C. Bascuñán; Relaciones fronterizas en la Araucanía: 107-173. Santiago de Chile, Ediciones Universidad Católica de Chile.

» Molina, J. I. ([1787] 1795). Compendio de la Historia Civil del Reyno de Chile. Escrito en Italiano por el Abate Don Juan Ignacio Molina. Parte Segunda. Madrid, Imprenta de Sancha.

»Pardo, O. (2004). Las chichas en el Chile precolombino. Chloris Chilensis 7 (2). Disponible en Internet: http://www.chlorischile.cl/chichas/chichas.htm. Consultada el: 10 de febrero de 2019.

»Pérez García, J. A. ([1810] 1900). Historia de Chile. Tomo I. En Colección de Historiadores de Chile y Documentos Relativos a la Historia Nacional, Tomo XXII: 11-504. Santiago de Chile, Imprenta Elzeviriana.

» Pinto Rodríguez, J. (1990). Frontera, misiones y misioneros en Chile, la Araucanía (16oo1900) en Pinto Rodríguez, J.; Casanova Guarda, H.; Uribe Gutiérrez, S. y M. Matthei; Misioneros en la Araucanía, 1600-1900: un capítulo de historia fronteriza en Chile: 19-154. Bogotá, CELAM.

» Pinto Rodríguez, J. (1991). “Entre el pecado y la virtud. Mortificación del cuerpo, misticismo y angustia en la temprana evangelización del Perú, Paraguay y Chile" en Pinto Rodríguez, J.; Salinas, M. y R. Föerster; Misticismo y violencia en la temprana evangelización de Chile: 1-31. Temuco, Ediciones Universidad de la Frontera.

»Poblete, M. P. (2019). El trabajo de niños y niñas mapuche-huilliches como "mocitos" y “chinitas" de servicio (Valdivia, siglos XVIII y XIX). Revista Chilena de Antropología 40: 221-237.

» Romano, R. (1965). Una economía colonial: Chile en el siglo XVIII. Buenos Aires, EUDEBA.

» Saignes, T. (1993). Borracheras andinas. ¿Por qué los indios ebrios hablan en español? en Saignes, T. (comp.); Borrachera y memoria: la experiencia de lo sagrado en los Andes: 43-71. La Paz, HISBOL/ IFEA.

»Salazar-Soler, C. (1993). Embriaguez y visiones en los Andes. Los Jesuitas y las “borracheras" indígenas en el Perú (Siglos XVI y XVII) en Saignes, T. (comp.); Borrachera y memoria: la experiencia de lo sagrado en los Andes: 23-42. La Paz, HISBOL/ IFEA.

»Salinas, M. (1991). El evangelio, el imperio español y la opresión contra los mapuches: el padre Luis de Valdivia en Chile, 1593-1619 en J. Pinto, J.; Salinas, M y R. Föerster: Misticismo y violencia en la temprana evangelización de Chile: 71-167. Temuco, Ediciones Universidad de la Frontera.

»Solano, F. (ed.). ([1780] 1994). Relaciones Económicas del Reino de Chile (1780). Madrid, CSIC/ Centro de Estudios Históricos.

»Solano, F. (ed.). ([1756] 1995) Relaciones Geográficas del Reino de Chile. 1756. Madrid/ Santiago de Chile, CSIC/ Universidad Internacional SEK.

» Sosa, P. de ([1616] 1898). “Memorial del peligroso estado espiritual, y temporal del Reyno de Chile" en Medina, J. T.; Biblioteca Hispano-Chilena II: 158-193. Santiago de Chile, En casa del autor. 
»Sosa, P. de ([s.d.] 1898). "Señor. Fray Pedro de Sosa, [...] de quan nociuos han sido los medios que se han executado en el Reyno de Chile" en Medina, J. T.; Biblioteca HispanoChilena II: 193-208. Santiago de Chile, En casa del autor.

» Téllez, E.; Denegri, F.; Ortiz, J. G. Alburquerque, G.; Málaga, A.; Castro, Y.; Gutiérrez, R. y M. Flores (2015). “La conformación del tejido comercial chileno-peruano" en Téllez E. y G. Alburquerque (dirs.); Historia de las relaciones comerciales formativas de Chile con Perú: Orígenes coloniales y alborada de la Independencia: 11-70. Santiago de Chile, Universidad Bernardo O’Higgins.

»Valenzuela Márquez, J. (2007). La cordillera de los Andes como espacio de circulaciones y mestizajes: un expediente sobre Chile central y Cuyo a fines del siglo XVIII. Nuevo Mundo Mundos Nuevos. Debates. Disponible en Internet: https://journals.openedition.org/ nuevomundo/7102?lang=en. Consultada el: 15 de diciembre de 2019.

»Valenzuela Márquez, J. (2014). Indios de arriba en Santiago de Chile según los registros de bautismo: entre el auge esclavista, la reconstrucción urbana y el abolicionismo (1665-1685). Chungará 46 (4): 625-636.

»Villalobos, S. (1989). “Guerra y paz en la Araucanía: Periodificación” en Villalobos, S y J. Pinto Rodríguez (comps.); Araucanía. Temas de Historia Fronteriza: 1-30. Temuco, Ediciones Universidad de la Frontera.

»Villalobos, S. (2002). Chile y su historia. Santiago de Chile, Editorial Universitaria.

»Villalobos, S. ([1968] 2009). El comercio y la crisis colonial. Santiago de Chile, Ediciones Akhilleus.

»Villar, D. y J. F. Jiménez (2001). “Para servirse de ellos”. Cautiverio, ventas a la usanza del pays y rescate de indios en las Pampas y Araucanía (Siglos XVII-XIX). Relaciones de la Sociedad Argentina de Antropología 26: 31-55.

»Villar, D. y J. F. Jiménez (2007). Convites: comida, bebida, poder y política en las sociedades indígenas de las pampas y Araucanía. Anuario IEHS 22: 241-272.

»Weber, D. J. (2005). Bárbaros: Spaniards and their Savages in the Age of Enlightenment. New Haven \& London, Yale University Press.

»Zavala Cepeda, J. M. (2008). Los mapuches del siglo XVIII: dinámica interétnica y estrategias de resistencia. Santiago de Chile, Editorial Universidad Bolivariana.

»Zavala Cepeda, J. M. (ed.) (2015). Los parlamentos hispano-mapuches, 1593-1803: textos fundamentales. Temuco, Ediciones Universidad Católica de Temuco. 